\title{
Comportamento ingestivo de novilhas de corte em pastagem de gramíneas anuais de estação quente ${ }^{1}$
}

\section{Alexandre Nunes Motta de Souza ${ }^{2}$, Marta Gomes da Rocha ${ }^{3}$, Luciana Pötter ${ }^{3}$, Dalton Roso ${ }^{3}$, Carine Lisete Glienke ${ }^{3}$, Renato Alves de Oliveira Neto ${ }^{3}$}

\footnotetext{
1 Pesquisa financiada pelo CNPq.

2 Instituto Federal Farroupilha - Campus São Vicente do Sul/RS.

${ }^{3}$ Universidade Federal de Santa Maria.
}

RESUMO - O experimento foi conduzido com o objetivo de avaliar os atributos das pastagens de milheto (Pennisetum americanum) e papuã (Urochloa plantaginea) e relacioná-los ao comportamento ingestivo de novilhas de corte. O delineamento experimental foi o inteiramente casualizado, com medidas repetidas no tempo, com dois tratamentos e duas repetições de área. O método de pastejo foi de lotação contínua e número variável de animais para manter a altura do dossel em $40 \mathrm{~cm}$. As massas de lâmina foliar, colmo e material morto, a taxa de acúmulo de forragem, a relação folha/colmo, oferta de forragem e de lâmina foliar, teor de fibra em detergente neutro foram semelhantes em milheto e papuã. O papuã apresentou maior densidade de colmo no estrato de $0-15 \mathrm{~cm}$ de altura. A densidade de material morto no estrato de $0-15 \mathrm{~cm}$ e as densidades de lâmina foliar, de colmo e de material morto nos estratos de $15-30 \mathrm{~cm}$, de $30-45 \mathrm{~cm}$ e mais de $45 \mathrm{~cm}$ de altura foram semelhantes em milheto e papuã. O comportamento ingestivo das novilhas, medido pelos tempos de pastejo, de ruminação e de ócio, taxa de bocado, massa do bocado, bocados por estação alimentar, estações alimentares por minuto e taxa de deslocamento, foi semelhante quando mantidas em milheto ou papuã. As equações de regressão múltipla, considerando os atributos do pasto, da pastagem e do clima apresentaram coeficientes de determinação acima de 0,70 para tempo de pastejo, massa do bocado, bocados por estação alimentar, estações alimentares por minuto, taxa de deslocamento e podem ser utilizadas como preditores do comportamento ingestivo de novilhas de corte em pastagens de milheto ou papuã.

Palavras-chave: estações alimentares, milheto, papuã, taxa de bocado, tempo de pastejo

\section{Ingestive behavior of beef heifers in warm season annual grass pastures}

\begin{abstract}
The experiment was carried out with the objective of evaluating attributes of pearl millet (Pennisetum americanum) and Alexander grass (Urochloa plantaginea) pastures and to relate them with ingestive behavior of beef heifers The experimental design was complete randomized, with repeated measures over time, with two treatments and two area replications. Grazing method was continuos stocking and variable number of animals to keep canopy height at $40 \mathrm{~cm}$. Mass of leaf blade, stem and dead material, forage accumulation rate, leaf/stem ratio, offer of forage and leaf blade, content of neutral detergent fiber were all similar in pearl millet and Alexander grass. Alexander grass presented higher stem bulk density in the 0-15 cm stratum. The density of dead material in the $0-15 \mathrm{~cm}$ stratum and the densities of leaf blade, stem and dead material in 15-30 cm, 30-45 cm and more than $45 \mathrm{~cm}$ in height strata were similar in millet and Alexander grass. The ingestive behavior of heifers, measured by grazing, rumination and idle times, bite rate, bite weight, bite per feeding station, feeding stations per minute and rate of displacement was similar when animals were kept in pearl millet or alexandergrass pastures. Multiple regression equations, considering atributes of pasture, grazing and climate showed determination coefficients greater than 0.70 for grazing time, bite mass, bite by feeding station, feeding station per minute, rate of displacement and they can be used as predictors of the ingestive behavior of beef heifers in pearl millet or alexandergrass pastures.
\end{abstract}

Key Words: alexandergrass, bite rate, feeding stations, grazing time, pearl millet

\section{Introdução}

No Sul do Brasil, a utilização de forrageiras tropicais vem sendo explorada para viabilizar os sistemas de criação de bovinos de corte a custos mais baixos, contribuindo para a redução do ciclo de recria e terminação. Dentre as espécies utilizadas estão as forrageiras de ciclo anual como o milheto (Pennisetum americanum) e o papuã (Urochloa plantaginea). O milheto é a forrageira tropical mais utilizada no Rio Grande do Sul (Montagner et al., 2008) enquanto o 
papuã, mesmo sendo considerada uma planta invasora de lavouras, já evidenciou o seu potencial para utilização em pastejo (Restle et al., 2002).

O comportamento ingestivo dos herbívoros é influenciado pela estrutura do dossel, caracterizada pela altura, relação folha/colmo, densidade de forragem e massa de lâmina foliar, pelas características químicas e digestibilidade da forragem. Além dessas variáveis, combinam-se outros fatores não relacionados à planta tais como a temperatura ambiente (Sollenberger \& Burns, 2001).

A estrutura do pasto determina o grau de facilidade na ingestão de alimento e afeta o consumo, por influenciar a massa do bocado, a taxa de bocado e o tempo de pastejo (Stobbs, 1973). O estabelecimento de metas de manejo para cada forrageira, orientadas pela estrutura do dossel, com objetivo de potencializar o crescimento do pasto e a sua ingestão é de utilidade para a transferência de tecnologias para os sistemas de produção (Silva \& Carvalho, 2005). O grande número de espécies utilizadas, as diferenças morfológicas entre elas e a amplitude de manejo são alguns dos fatores que dificultam a utilização de espécies forrageiras tropicais (Sollenberger \& Burns, 2001). Neste contexto, para o estabelecimento de metas de manejo fundamentadas nas estruturas do pasto, pode ser útil a utilização de modelos de predição usando análises multivariadas, que permitem avaliar ao mesmo tempo o efeito de um grande número de variáveis sobre o comportamento ingestivo e selecionar aquelas de maior relação com a variável resposta (Rego et al., 2006).

O presente experimento foi conduzido com o objetivo de avaliar os atributos estruturais do dossel forrageiro e composição química da forragem aparentemente consumida em milheto e papuã e relacioná-los com o comportamento ingestivo de novilhas de corte por meio de equações de regressão múltipla para as variáveis determinantes da atividade de pastejo, padrões de ingestão, de busca de estações alimentares e de deslocamento.

\section{Material e Métodos}

Foi avaliado o comportamento ingestivo de novilhas de corte em milheto (Pennisetum americanum) e papuã (Urochloa plantaginea) em experimento desenvolvido no Departamento de Zootecnia da Universidade Federal de Santa Maria.

A utilização das pastagens ocorreu entre 28/1 a 22/4/2007, totalizando 84 dias. A área experimental correspondeu a 4,5 hectares, com quatro divisões de 0,75 hectare, as quais constituíram as unidades experimentais e uma área contígua de 1,5 hectares. O clima da região é do tipo Cfa (subtropical úmido) conforme classificação de Köppen. O solo da área experimental pertence à unidade de mapeamento São Pedro e é classificado como Argissolo Vermelho distrófico arênico (EMBRAPA, 2006). As amostras de solo coletadas mostraram as seguintes características químicas: $\mathrm{pH}-\mathrm{H}_{2} \mathrm{O}$ : 5,0; índice SMP: 5,6; \% argila: $19,0 \mathrm{~m} / \mathrm{V} ; \mathrm{P}: 10,7 \mathrm{mg} / \mathrm{L}$; $\mathrm{K}: 110,0 \mathrm{mg} / \mathrm{L} ; \%$ MO: $2,7 \mathrm{~m} / \mathrm{V}$; Al: 0,8 cmolc/L; Ca: 3,8 cmolc/L; Mg: 1,8 cmolc/L; saturação de bases: $45,6 \%$ e saturação de $\mathrm{Al}: 13,4 \%$.

Para estabelecer as pastagens, a semeadura do milheto ocorreu em 23/12/06, com semeadora em linha, com preparo mínimo da área enquanto nas áreas de papuã somente foram realizadas duas gradagens, em 14/12. Foram utilizados $330 \mathrm{~kg} /$ hectare de adubo N-P-K da fórmula 05-20-20. A quantidade de nitrogênio aplicado em cobertura foi de $45 \mathrm{~kg} /$ hectare, na forma de uréia, em duas aplicações, em 31/1 e 20/2/07.

A massa de forragem foi determinada pela técnica de estimativa visual com dupla amostragem, realizada a cada 10 dias (Gardner, 1986) e a altura do dossel (cm) foi medida, na mesma ocasião, em 20 pontos por unidade amostral. A altura foi considerada como sendo a distância $(\mathrm{cm})$ do solo até a altura média do dobramento das folhas. Para manter a altura pretendida do dossel forrageiro em $40 \mathrm{~cm}$, o método de pastejo foi o continuo com número variável de animais (Heringer \& Carvalho, 2002).

A forragem proveniente dos cortes foi homogeneizada e dividida em duas amostras: uma para determinação do teor de matéria seca do pasto e outra para separação botânica e morfológica (lâmina foliar, pseudocolmo (colmo + bainha foliar) e material morto). Essas amostras foram pesadas e secas em estufa de ventilação forçada a $65^{\circ} \mathrm{C}$ por 72 horas. A partir da determinação da percentagem da lâmina foliar, de colmo e de material morto, foram calculadas as massas de lâmina foliar, de colmo e de material morto $(\mathrm{kg} / \mathrm{hectare}$ de matéria seca). As demais avaliações do pasto aconteceram no início e no final de cada período de 21 dias. A relação folha/colmo foi estimada por meio da divisão do valor da massa de lâmina foliar pelo valor da massa de colmos e foi expressa em $\mathrm{kg}$ de matéria seca de folhas/kg de matéria seca de colmos. A taxa de acúmulo diário de forragem ( $\mathrm{kg} /$ hectare/dia de matéria seca) foi determinada com três gaiolas de exclusão ao pastejo por unidade experimental.

A carga animal, em $\mathrm{kg} / \mathrm{hectare}$ de peso corporal foi obtida pela equação: [peso corporal médio das novilhasteste + (peso corporal animais reguladores $\times$ dias de permanência no piquete)/dias do período]. A oferta de forragem foi calculada pela divisão da disponibilidade diária de forragem (massa de forragem/21 dias + taxa diária de acúmulo de forragem) pela carga animal média do período. 
A oferta de lâmina foliar foi estimada pela multiplicação da oferta de forragem pela percentagem de lâmina foliar no pasto. No cálculo da oferta de forragem e oferta de lâmina foliar, os valores foram multiplicados por $100 \mathrm{e}$ apresentados em $\mathrm{kg}$ de matéria seca/100 $\mathrm{kg}$ de peso corporal.

Os valores de fibra em detergente neutro e de matéria seca foram avaliados na forragem proveniente da simulação de pastejo (Euclides et al., 1992) e foram determinados conforme as técnicas descritas pela Association of Official Analytical Chemists (1995).

Em cinco ocasiões (28/1,17/2,10/3,31/3 e 21/4), em cada unidade experimental, a estrutura vertical do pasto foi avaliada em três áreas representativas da altura pretendida do dossel. Foram avaliados os estratos de $0-15 \mathrm{~cm}, 15-30 \mathrm{~cm}$, $30-45 \mathrm{~cm}$ e acima de $45 \mathrm{~cm}$ de altura de dossel, em quadrados de $1 \mathrm{~m}^{2}$ de área. Em cada estrato a forragem foi cortada, acondicionada em sacolas e posteriormente separada em lâmina foliar, colmo + bainha foliar e material morto. Os valores foram expressos em percentagem e multiplicados pelo valor da massa de forragem do período. A densidade de forragem de cada componente estrutural nos estratos foi calculada dividindo-se a massa observada $(\mathrm{kg} / \mathrm{hectare}$ de matéria seca) por $15 \mathrm{~cm}$, apresentando os resultados em kg/hectare/cm de matéria seca.

As perdas de forragem foram determinadas por meio da metodologia proposta por Hillesheim (1998). Foram colocados 10 pontos amostrais em cada potreiro, por meio de duas estacas de madeira enterradas no solo, ficando com aproximadamente $20 \mathrm{~cm}$ acima do solo e entre elas e a cada 28 dias colocou-se quadrados de $0,25 \mathrm{~m}^{2}$ e coletou-se a forragem considerada não aproveitável pelos animais (material senescente, morto ou danificado pelo pisoteio e dejeções). As amostras foram levadas para estufa, secas e pesadas. A quantidade de MS obtida foi extrapolada da área total coletada $\left(0,25 \mathrm{~m}^{2} \times 10\right.$ pontos amostrais $)$ para um hectare, e assim determinou-se a perda de forragem por período e por potreiro em $\mathrm{kg} / \mathrm{ha}$ de MS.
O desaparecimento de forragem $(\mathrm{kg} /$ hectare de matéria seca) foi calculado pela equação: (desaparecimento de forragem $=$ produção total de matéria seca - massa de forragem final - perdas de forragem) e, dividido pelo número de dias do período, resultando no desaparecimento diário de forragem. O desaparecimento diário de forragem, divido pela carga animal, resultou no consumo estimado de forragem. A eficiência de utilização do pasto foi calculada pela seguinte equação: (desaparecimento diário de forragem/produção total de matéria seca)*100, e expresso em percentagem.

Em cada unidade experimental permaneceram quatro novilhas-teste da raça Polled Hereford, com 15 meses de idade e peso corporal inicial de $278 \pm 20,0 \mathrm{~kg}$ e um número variável de animais reguladores. As novilhas tiveram livre acesso à água e sal mineral e, antes das pesagens, foram submetidas a jejum prévio de sólidos e líquidos, por 12 horas.

As avaliações do comportamento ingestivo foram realizadas nos dias 10/2,5/3,27/3 e 15/4/2007, em períodos contínuos de 24 horas, sem ocorrência de chuvas. Os dados climáticos foram obtidos junto a Estação meteorológica da Universidade Federal de Santa Maria (Tabela 1).

As avaliações do comportamento ingestivo foram realizadas por meio de observação visual (Jamieson \& Hodgson, 1979), com intervalos de dez minutos. Foram observadas quatro novilhas-teste, por piquete e suas atividades foram classificadas como pastejo, ruminação e ócio. O tempo de pastejo foi considerado como o tempo gasto pelos animais na seleção e apreensão da forragem, incluindo o deslocamento entre as estações de pastejo utilizados para a seleção da dieta (Hancock, 1953). O tempo de ruminação foi identificado por meio da cessação do pastejo e da realização da atividade de mastigação. O tempo de ócio correspondeu ao período no qual o animal permaneceu em descanso (Forbes, 1988). O tempo gasto pelo animal para realizar 20 bocados foi registrado, a cada

Tabela 1 - Dados de temperatura e horas diárias de insolação nas datas de avaliações, médias mensais de janeiro a abril de 2007 e médias históricas de temperatura e precipitação pluviométrica

\begin{tabular}{|c|c|c|c|c|}
\hline & $10 / 2 / 2007$ & $5 / 3 / 2007$ & $27 / 3 / 2007$ & $15 / 4 / 2007$ \\
\hline Temperatura máxima $\left({ }^{\circ} \mathrm{C}\right)$ & 32,6 & 31,2 & 32,2 & 29,0 \\
\hline Temperatura mínima $\left({ }^{\circ} \mathrm{C}\right)$ & 18,8 & 24,0 & 20,7 & 18,0 \\
\hline Temperatura média $\left({ }^{\circ} \mathrm{C}\right)$ & 25,7 & 27,6 & 26,5 & 23,5 \\
\hline Horas diárias de insolação & Janeiro & Fevereiro & Março & Abril \\
\hline Precipitação pluviométrica (mm) & 227,0 & 145,2 & 188,6 & 121,9 \\
\hline Temperatura média $\left({ }^{\circ} \mathrm{C}\right)^{1}$ & 24,6 & 24,0 & 22,2 & 18,0 \\
\hline
\end{tabular}

${ }^{1}$ Médias históricas de 1961 a 2007. 
10 minutos, durante o período diurno, sempre que o animal estivesse em atividade de pastejo, para calcular a taxa de bocado/minuto (Hodgson, 1982), cujo valor multiplicado pelo tempo de pastejo, resultou no número diário estimado de bocados. Para o cálculo da massa do bocado, dividiu-se o consumo de estimado de forragem pelo número diário de bocados (Jamieson \& Hodgson, 1979).

Em cada avaliação do comportamento ingestivo as variáveis relacionadas com as estações alimentares foram medidas cinco vezes no turno da manhã e cinco no turno da tarde. As variáveis observadas foram: tempo gasto pelas novilhas para percorrer 10 estações alimentares e o número de passos dados entre as estações. Uma estação alimentar foi considerada como o espaço correspondente ao pastejo, sem movimento das patas dianteiras (Laca et al., 1992) e um passo foi definido como cada movimento das patas dianteiras. A partir desses dados foram estimados a taxa de deslocamento (passos/minuto) e o número diário de estações alimentares. O número de bocados por estação foi calculado pela divisão entre o número diário de bocados e número diário de estações alimentares. O número de estações por minuto foi calculado pela divisão do número diário de estações pelo tempo de pastejo.

O delineamento experimental foi o inteiramente casualizado, com medidas repetidas no tempo, com dois tratamentos e duas repetições de área. Os dados foram submetidos à análise de variância e teste $\mathrm{F}$ em nível de 5\% de significância. As análises de comparação de médias foram efetuadas utilizando-se o procedimento MIXED e estrutura de covariâcia Simetria Composta (SAS, 2001). Foram realizadas análises de regressão polinomial pelo procedimento GLM, considerando a variável período ( $\mathrm{X}=$ dias), de correlação linear de Pearson pelo procedimento CORR e regressão múltipla pelo procedimento STEPWISE $($ Forward $=0,05)$. O modelo matemático geral referente à análise das variáveis estudadas foi representado por: $\mathrm{Y}_{\mathrm{ijk}}=\mu+\mathrm{T}_{\mathrm{i}}+\mathrm{R}_{\mathrm{k}}\left(\mathrm{T}_{\mathrm{i}}\right)+\mathrm{P}_{\mathrm{j}}+(\mathrm{TP})_{\mathrm{ij}}+\varepsilon_{\mathrm{ijk}}$; onde, $\mathrm{Y}_{\mathrm{ijk}}$ representa as variáveis dependentes; $\mu$ é a média de todas as observações; $T_{i}$ corresponde ao efeito da i-ésima espécie forrageira; $R_{k}\left(T_{i}\right)$ é o efeito da k-ésima repetição dentro do i-ésimo tratamento (erro a); $\mathrm{P}_{\mathrm{j}}$ é o efeito do j-ésimo período; $(\mathrm{TP})_{\mathrm{ij}}$ representa a interação entre a i-ésima espécie forrageira e oj-ésimo período; e $\varepsilon_{\mathrm{ijk}}$ corresponde ao erro experimental residual (erro b).

\section{Resultados e Discussão}

A altura do dossel observada, média de $40,1 \mathrm{~cm}$, foi semelhante em milheto e papuã e para a mesma altura de dossel, os valores de massa de forragem foram maiores em papuã (Tabela 2). Isso evidencia as limitações do uso da massa de forragem como a única variável de controle da vegetação, fato já observado por Carvalho (1997). Conforme esse autor, uma mesma massa de forragem pode se apresentar de diversas formas no espaço, devido às diversas combinações possíveis de altura e densidade. Mesmo que as massas de forragem tenham sido distintas nas espécies avaliadas, não foram observadas diferenças para as massas de lâmina foliar, de colmo e de material morto ( $\mathrm{P}>0,05$; Tabela 2). Provavelmente esse resultado foi devido ao somatório das massas de cada componente medido (folha, colmo e material morto) que apresentaram valores numéricos maiores em papuã.

A oferta de forragem e a oferta de lâmina foliar foram semelhantes $(\mathrm{P}>0,05)$ em milheto e papuã (Tabela 2$)$. A oferta de lâmina foliar se ajustou ao modelo quadrático de regressão ( $\left.\hat{Y}=4,14+0,07 \mathrm{X}-0,001 \mathrm{X}^{2} ; \mathrm{r}^{2}=0,81 ; \mathrm{P}=0,0001\right)$, com ponto de máxima de $5,4 \mathrm{~kg}$ de matéria seca $/ 100 \mathrm{~kg}$ de peso corporal no $35^{\circ}$ dia de utilização. Mesmo com o comportamento quadrático da oferta de lâmina foliar, os valores dessa variável no início e final de utilização da pastagem ainda mantiveram-se acima de 2,7 kg de matéria $\mathrm{seca} / \mathrm{kg}$ de peso corporal, que corresponde ao consumo potencial de matéria seca por novilhas de corte com 18 meses de idade (NRC, 1996).

Tabela 2 - Valores médios de parâmetros da pastagem e do pasto

\begin{tabular}{|c|c|c|c|c|c|}
\hline \multirow[b]{2}{*}{ Parâmetros } & \multicolumn{2}{|c|}{ Espécie } & \multirow{2}{*}{$\begin{array}{c}\text { Erro } \\
\text { Padrão }\end{array}$} & \multirow[b]{2}{*}{$\mathrm{P}^{2}$} & \multirow[b]{2}{*}{$\mathrm{E} \times \mathrm{D}^{3}$} \\
\hline & Milheto & Papuã & & & \\
\hline Altura do dossel & 41,3 & 38,9 & 2,08 & 0,4397 & 0,0696 \\
\hline Massa de lâmina foliar & 720,4 & 984,6 & 107,11 & 0,1333 & 0,0571 \\
\hline Massa de colmos & $1.265,4$ & $1.707,2$ & 168,10 & 0,1194 & 0,0587 \\
\hline Massa de material morto & 304,6 & 368,2 & 25,39 & 0,1904 & 0,0929 \\
\hline Oferta de lâmina foliar & 3,5 & 4,1 & 0,46 & 0,5158 & 0,1007 \\
\hline Fibra em detergente neutro, $\%$ & 51,8 & 54,5 & 0,64 & 0,2569 & 0,2164 \\
\hline Matéria seca, \% & 16,2 & 19,3 & 0,27 & 0,0255 & 0,2168 \\
\hline
\end{tabular}

\footnotetext{
${ }^{1}$ Erro-padrão residual; ${ }^{2}$ Probabilidade; ${ }^{3}$ Probabilidade da interação espécie $\times$ dia de utilização
} 
O teor de fibra em detergente neutro no pasto coletado por simulação de pastejo foi semelhante em ambas as espécies, com valor médio de $53,2 \%$ ( $\mathrm{P}>0,05$; Tabela 2). O manejo de milheto e papuã com altura do dossel de $40 \mathrm{~cm}$, provavelmente não tenha limitado o consumo voluntário de forragem pelos animais em pastejo, pois a estrutura formada no dossel propiciou oferta de lâmina foliar maior que o consumo previsto de matéria seca em todo período de utilização dos pastos, permitindo aos animais selecionarem porções de maior qualidade do dossel forrageiro, com teor de fibra em detergente neutro menor que $55 \%$, considerado como limitante para o consumo de matéria seca pelos bovinos (Van Soest, 1994). Em milheto, no entanto, a ingestão de forragem pelos animais pode ter sido limitada pelo teor de matéria seca, cujo valor (Tabela 2) esteve abaixo de 18\%, considerado por Alberto (1997) como o teor mínimo para que não ocorra restrição de consumo.

A densidade de lâmina foliar apresentou interação $(\mathrm{P}<0,05)$ espécie $\times$ dia de utilização no estrato de $0-15 \mathrm{~cm}$ de altura do dossel (Tabela 3 ). No milheto, a densidade de lâmina foliar se ajustou ao modelo linear de regressão ( $\left.\hat{\mathrm{Y}}=19,43-0,10 \mathrm{X} ; \mathrm{r}^{2}=0,85 ; \mathrm{P}=0,0011\right)$, enquanto no papuã essa densidade se manteve constante durante o período experimental.

Esse comportamento no papuã seria desejável do ponto de vista de manejo e nutrição dos animais, pois como já observado por Genro (1999), em pastagens tropicais, o consumo máximo ocorreu quando os animais estavam em pastagens com alta densidade de folhas acessíveis. Os estratos mais acessíveis, no entanto, são os estratos superiores e neste caso, em milheto e papuã, a densidade de folhas se comportou de forma semelhante ( $\mathrm{P}>0,05$; Tabela 3$)$, diminuindo essa densidade com o aumento do dossel forrageiro.

A densidade de colmos foi maior ( $\mathrm{P}>0,05)$ em papuã no estrato de $0-15 \mathrm{~cm}$ de altura e se ajustou ao modelo linear de regressão ( $\left.\hat{\mathrm{Y}}=48,7+0,43 \mathrm{X} ; \mathrm{r}^{2}=0,58 ; \mathrm{P}=0,0271\right)$. Também no milheto, o ajuste foi para o modelo linear de regressão $\left(\hat{\mathrm{Y}}=15,9+0,57 \mathrm{X} ; \mathrm{r}^{2}=0,77 ; \mathrm{P}=0,0043\right)$.

Nos estratos intermediários (15-30 e 30-45 cm) e no estrato superior (acima de $45 \mathrm{~cm}$ ) não foram observadas diferenças entre as espécies avaliadas para as densidades de lâmina foliar, de colmo e de material morto. Com o aumento da altura do dossel observou-se redução na densidade de todos os componentes estruturais (Tabela 3 ), fato também observado por Heringer \& Moojen (2002) e Martinichen (2006).

As variáveis do comportamento ingestivo das novilhas foram semelhantes $(\mathrm{P}>0,05)$ em milheto e papuã (Tabela 4$)$ e podem ser explicadas pela semelhança $(\mathrm{P}>0,05)$ na composição química e nas principais características estruturais do pasto e da pastagem que afetam o comportamento ingestivo, tais como: a altura de dossel, massa de lâmina foliar, relação folha/colmo (Sollenberger \& Burns, 2001), oferta de forragem, oferta de lâmina foliar, densidade de forragem (Carvalho, 1997) e teor de fibra em detergente neutro (Van Soest, 1994).

A distribuição diária das atividades de pastejo, ócio e ruminação foi de 8 horas e 40 minutos, 8 horas e 23 minutos e 6 horas e 57 minutos, respectivamente, e os resultados estão dentro da amplitude de valores observada em resultados de vários experimentos com espécies forrageiras tropicais (Brâncio et al., 2003; Sarmento, 2003; Palhano et al., 2006).

A taxa de bocado e massa do bocado apresentaram valores médios em milheto e papuã de 26,9 bocados/minuto e 1,2 g de matéria seca/bocado. Esse valor de massa do bocado é cerca de quatro vezes maior que o valor crítico considerado por Stobbs (1973) para manutenção da ingestão diária de matéria seca. Isso reitera a afirmação de não ter existido limitação ao consumo voluntário, quando foram levados em consideração os valores de oferta de lâmina foliar e teor de fibra em detergente neutro. Valores lineares

Tabela 3 - Valores médios e de probabilidade da densidade dos componentes morfológicos nos estratos de 0-15 cm, de 15-30 cm, de $30-45 \mathrm{~cm}$ e acima de $45 \mathrm{~cm}$ de altura do dossel forrageiro $(\mathrm{kg} / \mathrm{ha} / \mathrm{cm}$ de matéria seca)

\begin{tabular}{|c|c|c|c|c|c|}
\hline \multirow[b]{2}{*}{ Densidade } & \multicolumn{2}{|c|}{ Espécie } & \multirow{2}{*}{$\begin{array}{c}\text { Erro } \\
\text { Padrão }{ }^{1}\end{array}$} & \multirow[b]{2}{*}{$\mathrm{P}^{2}$} & \multirow[b]{2}{*}{$\mathrm{E} \times \mathrm{D}^{3}$} \\
\hline & Milheto & Papuã & & & \\
\hline Lâmina foliar, $0-15 \mathrm{~cm}$ & 15,0 & 20,6 & 2,79 & 0,3537 & 0,0143 \\
\hline Lâmina foliar, $15-30 \mathrm{~cm}$ & 13,0 & 20,2 & 1,30 & 0,1285 & 0,2896 \\
\hline Lâmina foliar, $30-45 \mathrm{~cm}$ & 13,1 & 13,8 & 3,79 & 0,8684 & 0,3981 \\
\hline Lâmina foliar, acima de $45 \mathrm{~cm}$ & 5,3 & 6,1 & 2,45 & 0,7998 & 0,0657 \\
\hline Colmos, $0-15 \mathrm{~cm}$ & 40,1 & 66,9 & 2,02 & 0,0438 & 0,6003 \\
\hline Colmos, $15-30 \mathrm{~cm}$ & 24,6 & 29,9 & 3,67 & 0,2855 & 0,2270 \\
\hline Colmos, $30-45 \mathrm{~cm}$ & 11,5 & 11,8 & 4,17 & 0,9585 & 0,1635 \\
\hline Material morto, $0-15 \mathrm{~cm}$ & 22,8 & 32,2 & 0,16 & 0,0623 & 0,0768 \\
\hline Material morto, $15-30 \mathrm{~cm}$ & 3,2 & 2,8 & 0,27 & 0,2705 & 0,7589 \\
\hline
\end{tabular}

${ }^{1}$ Erro-padrão residual; ${ }^{2}$ Probabilidade; ${ }^{3}$ Probabilidade da interação espécie $\times$ dia de utilização. 
crescentes de massa de bocado foram observados por Sarmento (2003) em capim-marandu (Brachiaria brizantha Stapf cv. Marandu) com alturas de dossel variando de 10 a $40 \mathrm{~cm}$, com valor máximo de $1,5 \mathrm{~g}$ de matéria seca por bocado.

O número de bocados por estação alimentar, o número de estações alimentares por minuto e a taxa de deslocamento, considerados como resposta funcional do animal em pastejo à oferta de forragem (Laca \& Demment, 1992), foram semelhantes $(\mathrm{P}>0,05)$ entre as espécies avaliadas, com valores médios de 5,3 bocados, 5,9 estações e 9,5 passos por minuto, respectivamente.

$\mathrm{Na}$ análise de regressão múltipla, o tempo de pastejo das novilhas (Tabela 5) foi explicado pela altura do dossel (39\%) e pela temperatura mínima diária (33\%). Na análise do coeficiente de regressão parcial, observou-se que altura apresentou $9 \%$ a mais de importância na equação do que a temperatura mínima diária.

$\mathrm{Na}$ amplitude de altura do dossel observada de $40,1 \pm 10,1 \mathrm{~cm}$, o tempo de pastejo esteve correlacionado de forma positiva ( $\mathrm{r}=0,55 ; \mathrm{P}=0,0266)$ com a altura. A altura do dossel forrageiro é um parâmetro que determina a maior ou menor dificuldade de apreensão da forragem, pela massa de forragem e pela dificuldade física de apreensão (Carvalho et al., 2001) e os animais modificam o comportamento ingestivo quando ocorrem alterações na estrutura do pasto
(Sollenberger \& Burns, 2001). Como resposta funcional de curto prazo, para manter a taxa de ingestão diária de matéria seca, há aumento do tempo de pastejo (Laca \& Demment, 1992), conforme observado nas novilhas do experimento.

Dentre os fatores não relacionados ao pasto que devem ser considerados no comportamento ingestivo de bovinos está a temperatura ambiente (Hancock, 1953). Nesse experimento, a temperatura mínima diária afetou de forma negativa o tempo de pastejo (Tabela 5) e isso pode ser explicado pelo fato das temperaturas mínimas observadas (Tabela 1) estarem próximas do valor de $25^{\circ} \mathrm{C}$ considerado limitante à produção de bovinos de corte (Hahn, 1999) e podem promover decréscimo de consumo de matéria na ordem de $10 \%$ em temperaturas entre 25 e $35^{\circ} \mathrm{C}$ (Fox et al., 1988).

Parte do efeito das temperaturas mínimas no comportamento ingestivo pode também ser explicado pelo grupo genético das novilhas experimentais (Bos taurus), que são menos tolerantes ao calor que novilhas Bos indicus e, como resposta a esse estresse, apresentam menor desempenho produtivo e reprodutivo (Finch, 1986). Dentre os efeitos do estresse calórico estão o menor consumo de matéria seca e maior ingestão de água em novilhas Bos taurus quando comparadas com novilhas Bos indicus (Beatty et al.; 2006).

Tabela 4 - Valores médios das variáveis de comportamento ingestivo

\begin{tabular}{|c|c|c|c|c|c|}
\hline \multirow[b]{2}{*}{ Variáveis } & \multicolumn{2}{|c|}{ Espécie } & \multirow{2}{*}{$\begin{array}{c}\text { Erro } \\
\text { Padrão }\end{array}$} & \multirow[b]{2}{*}{$\mathrm{P}^{2}$} & \multirow[b]{2}{*}{$\mathrm{E} \times \mathrm{D}^{3}$} \\
\hline & Milheto & Papuã & & & \\
\hline Tempo de pastejo & 551,8 & 487,8 & 14,36 & 0,0591 & 0,4389 \\
\hline Tempo de ruminação & 428,2 & 405,9 & 13,93 & 0,4543 & 0,1372 \\
\hline Taxa de bocado & 26,1 & 27,6 & 1,88 & 0,5082 & 0,6238 \\
\hline Massa do bocado & 1,3 & 1,1 & 0,10 & 0,2766 & 0,4252 \\
\hline Taxa de deslocamento & 10,4 & 8,6 & 0,49 & 0,3885 & 0,1738 \\
\hline
\end{tabular}

${ }^{1}$ Erro-padrão residual; ${ }^{2}$ Probabilidade; ${ }^{3}$ Probabilidade da interação espécie $\times$ dias de utilização.

Tabela 5 - Equações de regressão múltipla das variáveis de comportamento ingestivo de novilhas de corte em pastagens de milheto e papuã

\begin{tabular}{|c|c|c|c|c|c|}
\hline Variável resposta & Variável & Estimativa & $\mathrm{r}^{2}$ parcial & $\mathrm{R}^{2}$ total & $\mathrm{P}$ \\
\hline \multirow[t]{3}{*}{ Tempo pastejo } & Intercepto & 516,20 & - & - & - \\
\hline & Altura dossel & 9,71 & 0,39 & - & 0,0166 \\
\hline & Temperatura mínima & $-19,13$ & 0,33 & 0,72 & 0,0037 \\
\hline \multirow[t]{3}{*}{ Massa do bocado } & Intercepto & 2,51 & - & - & - \\
\hline & Oferta forragem & 0,04 & 0,62 & - & 0,0008 \\
\hline & Fibra detergente neutro & $-0,04$ & 0,13 & 0,75 & 0,0392 \\
\hline \multirow{4}{*}{ Estações/minuto } & Intercepto & 10,83 & - & - & - \\
\hline & Densidade folha $15-30 \mathrm{~cm}$ & $-0,076$ & 0,55 & - & 0,0024 \\
\hline & Massa forragem & $-0,003$ & 0,18 & - & 0,0195 \\
\hline & Massa colmos & 0,003 & 0,15 & 0,88 & 0,0055 \\
\hline \multirow{4}{*}{ Tx Deslocamento } & Intercepto & 17,32 & - & - & - \\
\hline & Massa forragem & $-0,003$ & 0,76 & - & 0,0001 \\
\hline & Densidade folha ${ }^{0-15} \mathrm{~cm}$ & $-0,111$ & 0,19 & - & 0,0001 \\
\hline & Massa colmo & 0,002 & 0,02 & 0,97 & 0,0198 \\
\hline
\end{tabular}


A concentração da atividade de pastejo das novilhas aconteceu na ocasião na qual as temperaturas eram mais amenas, no amanhecer e no entardecer (Figura 1) quando mais de 50\% dos animais encontravam-se em atividade de pastejo.

A taxa de bocado não se ajustou ao modelo de regressão múltipla. A correlação entre taxa de bocado e massa do bocado foi de $-0,65(\mathrm{P}=0,0061)$ e, é esperado que a taxa de bocado esteja correlacionada de forma negativa com a massa do bocado (Hodgson et al., 1997). A mudança na taxa de bocado ocorre também como um mecanismo compensatório, aumentando quando o massa do bocado diminui, para manter constante a taxa de ingestão (Penning et al., 1991).

A oferta de forragem explicou $62 \%$ da variação da massa do bocado e na análise do coeficiente parcial de regressão, teve $64 \%$ a mais de efeito sobre o massa do bocado em comparação ao teor de fibra em detergente neutro (Tabela 5). A oferta de forragem se relacionou com a oferta de lâmina foliar ( $\mathrm{r}=0,93 ; \mathrm{P}<0,0001)$, indicando que, provavelmente, a quantidade de folhas presentes na oferta de forragem determinou um bocado mais pesado. Mesmo que Gordon \& Lascano (1993) tenham afirmado que o massa do bocado é determinado pela área do bocado e pela densidade forrageira, não houve correlação $(\mathrm{P}>0,05)$ entre massa do bocado e as medidas de densidade de forragem.

O teor de fibra em detergente neutro explicou de forma negativa $13 \%$ da massa do bocado e este teor está ligado ao estádio de desenvolvimento das forrageiras, aumentando linearmente ao longo do ciclo de utilização do pasto $\left(\hat{\mathrm{Y}}_{\mathrm{FDN}}=\right.$ $\left.48,51+0,11 \mathrm{X} ; \mathrm{r}^{2}=0,59 ; \mathrm{P}=0,0005\right)$. Esse aumento pode ser explicado pela redução linear da relação folha/colmo na planta $\left(\hat{\mathrm{Y}}_{\mathrm{RFC}}=1,0-0,01 \mathrm{X} ; \mathrm{r}^{2}=0,76 ; \mathrm{P}<0,0001\right)$ e os maiores valores de fibra em detergente neutro encontram-se nos colmos (Prache \& Peyraud, 1997).

A densidade de lâmina foliar no estrato de $15-30 \mathrm{~cm}$ de altura explicou $55 \%$ da variação do número de estações por minuto (Tabela 5) e quanto maior a densidade neste estrato, menor foi o número de estações percorridas pelos animais.

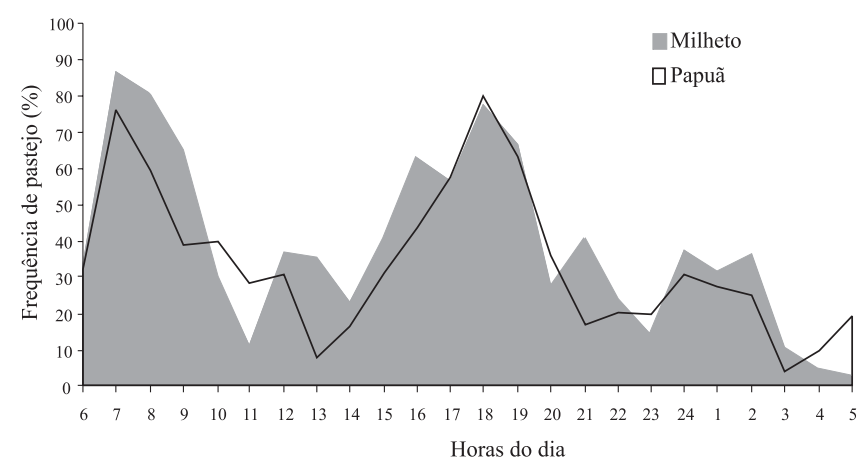

Figura 1 - Frequência de pastejo (\% de novilhas em pastejo) em pastagem de milheto (com preenchimento) ou papuã (sem preenchimento).
A importância da massa de forragem no número de estações alimentares por minuto é explicada por Bailey et al. (1996) de que a permanência do animal nas estações alimentares depende da concentração de nutrientes nela. A manipulação dos colmos na formação do bocado exige maior tempo e reduz o número de bocados (Stobbs, 1973), confirmando a importância da densidade de folhas na estação alimentar como fator determinante do tempo de permanência do animal (Carvalho \& Moraes, 2005). A massa de forragem explicou $18 \%$ da variação e a massa de colmos $15 \%$. Na análise do coeficiente parcial de regressão se observou que a massa de forragem e massa de colmos foram 317 e $205 \%$, respectivamente, mais relevantes que a densidade de lâmina foliar no estrato de $15-30 \mathrm{~cm}$ de altura.

A taxa de deslocamento foi explicada pela massa de forragem e pela densidade de lâmina foliar no estrato de 0-15 cm de altura de forma negativa em 76 e 19\%, respectivamente, e de forma positva em $2 \%$ pela massa de colmos (Tabela 5). Os coeficientes parciais de regressão demostraram que a massa de forragem é 185,8 e 105,2\% mais importante que a densidade de lâmina foliar no estrato de 0-15 cm de altura e a massa de colmo, respectivamente, na variação da taxa de deslocamento, possivelmente porque essa medida contempla todos os estratos do dossel forrageiro.

Os modelos de predição dos padrões de busca de estações alimentares e de deslocamento demonstraram que nas estações com maior quantidade de nutrientes, expressos por maior massa de forragem e maior densidade de lâmina foliar da base até o topo do dossel forrageiro, proporcionaram maior permanência do animal na estação alimentar. Na medida em que ocorreu aumento na proporção de colmos na estrutura do pasto, a mudança na estratégia de pastejo refletiu-se em menor número de bocados por estação, mais estações visitadas por minuto e maior taxa de deslocamento dos animais, ocasionando provavelmente, maiores gastos de tempo e energia na busca de sítios de pastejo de melhor qualidade, fato já descrito por Carvalho \& Moraes (2005).

\section{Conclusões}

As pastagens de milheto e papuã, quando manejadas a $40 \mathrm{~cm}$ de altura de dossel, apresentam composição estrutural e química semelhantes e não determinam alterações no comportamento ingestivo de novilhas Polled Hereford, medido pela atividade de pastejo, padrões de ingestão, de busca de estações alimentares e de deslocamento. Equações de regressão múltipla, considerando os atributos do pasto, da pastagem e os efeitos do clima, podem ser utilizadas como modelos preditores do comportamento ingestivo de novilhas de corte em pastagens de milheto ou papuã. 


\section{Agradecimentos}

Aos colaboradores do Setor de Fooragicultura do Departamento de Zootecnia da Universidade Federal de Santa Maria, pelo auxílio na condução do experimento, e ao Sr. Valter José Pötter da Estância Guatambu, Dom Pedrito, Rio Grande do Sul, pelo empréstimo das novilhas experimentais.

\section{Referências}

ALBERTO, E. Efectos de la calidad de los forrajes y la suplementación en el desempeño de ruminantes en pastoreo. In: JOBIM, C.C.; SANTOS, G.T.; CECATO, U. (Eds.) Simpósio sobre avaliação de pastagens com animais. Maringá: Cooper Graf. Artes Gráficas Ltda, 1997. p.53-73.

ASSOCIATION OF OFFICIAL ANALYTICAL CHEMISTS - AOAC. Official methods of analysis. 14.ed. Washington, 1995. $1141 \mathrm{p}$.

BAILEY, D.W.; GROSS, J.E.; LACA, E.A. et al. Mechanisms that result in large herbivore grazing distribution patterns. Journal of Range Management, v.49, p.386-400, 1996.

BEATTY, D.T.; BARNES, A.; TAYLOR, E. et al. Physiological responses of Bos taurus and Bos indicus cattle to prolonged, continuous heat and humidity. Journal Animal Sience, v. 84, n.4, p.972-984, 2006.

BRÂNCIO, P.A.; EUCLIDES, V.P.B.; NASCIMENTO JÚNIOR, D. do et al. Avaliação de três cultivares de Panicum maximum Jacq. sob pastejo: comportamento ingestivo de bovinos. Revista Brasileira de Zootecnia, v.23, n.5, p.1045-1053, 2003.

CARVALHO, P.C.F.; RIBEIRO FILHO, H.M.N; POLI, C.H.E.C et al. Importância da estrutura da pastagem na ingestão e seleção de dietas pelo animal em pastejo. In: MATTOS, W.R.S. (Org.). A produção animal na visão dos brasileiros. Piracicaba: Fundação de Estudos Agrários Luiz de Queiroz, 2001. p.853-871.

CARVALHO, P.C.F. A estrutura da pastagem e o comportamento ingestivo de ruminantes em pastejo. In: SIMPÓSIO SOBRE AVALIAÇÃO DE PASTAGENS COM ANIMAIS, 1997, Maringá. Anais... Maringá: CCA/UEM, 1997. p.25-52.

CARVALHO, P.C.F.; MORAES, A. Comportamento ingestivo de ruminantes: bases para o manejo sustentável do pasto. In: CECATO, U.; JOBIM, C.C. (Orgs.). Manejo sustentável em pastagem. Maringá: UEM, 2005. v.1, p.1-20.

EMPRESA BRASILEIRA DE PESQUISA EM AGROPECUÁRIA EMBRAPA. Centro Nacional e Pesquisa em Solos. Sistema Brasileiro de Classificação de Solos. Brasília: EmbrapaSPI; Rio de Janeiro: Embrapa-Solos, 2006. 306p.

EUCLIDES, V.P.B; MACEDO, M.C.M.; OLIVEIRA, M.P. Avaliação de diferentes métodos de amostragem sob pastejo. Revista Brasileira de Zootecnia, v.21, n.4, p.691-702, 1992.

FINCH, V.A. Body temperature in beef cattle: its control and relevance to production in the tropics. Journal of Animal Science, v.62, p.531-542, 1986.

FORBES, T.D.A. Researching the plant-animal interface: the investigation of ingestive behaviour of cows and sheep. Journal of Animal Science, v.66, p.2369-2379, 1988.

FOX, D.G.; SNIFFEN, C.J.; O'CONOR, J.D. Adjusting nutrient requirementes of beef cattle for animal and environmental variations. Journal of Animal Science, v.66, n.5, p.1475-1453, 1988.

GARDNER, A.L. Técnicas de pesquisa em pastagens e aplicabilidade de resultados em sistemas de produção. Brasília: IICA, 1986. 197p.

GENRO, T.C.M. Estimativas de consumo em pastejo e suas relações com os parâmetros da pastagem em gramíneas tropicais. 1999. 183f. Tese (Doutorado em Zootecnia) Universidade Federal do Rio Grande do Sul.

GORDON, I.J; LASCANO, C. Foraging strategies of ruminant livestock on intensively managed grasslands: potentials and constraints. In: INTERNATIONAL GRASSLANDS CONGRESS, 17., 1993, Hamilton. Proceedings... Hamilton: New Zeland, p.681-689, 1993.

HAHN, G.L. Dynamic responses of cattle to thermal heat loads Journal of Animal Science, v.77, p.10-20, 1999 (supp1. 2).

HANCOCK, J. Grazing behaviour of cattle. Animal Breeding Abstract, v.21, n.1, p.1-13, 1953.

HERINGER, I.; CARVALHO, P.C.F. Ajuste da carga animal em experimentos de pastejo: uma nova proposta. Ciência Rural, v.32, n.4, p.675-679, 2002.

HERINGER, I.; MOOJEN, E.L. Potencial produtivo, alterações da estrutura e qualidade da pastagem de milheto submetida a diferentes níveis de nitrogênio. Revista Brasileira de Zootecnia, v.31, n.2, p.875-882, 2002.

HILlESHEIM, A. Manejo do gênero Pennisetum sob pastejo. In: SIMPÓSIO SOBRE MANEJO DA PASTAGEM, 9., 1998, Piracicaba: Anais... Piracicaba: FEALQ, 1998. p.77-108.

HODGSON, J. Influence of sward characteristics on diet selection and herbage intake by the grazing animal. In: HACKER, J.B. (Ed.) Nutritional limits to animal production from pasture. Queensland: CAB, 1982. p.153-166.

HODGSON, J.; COSGROVE, G.P.; WOODWARD, S.J.R. Research on foraging behavior: progress and priorities. In: INTERNATIONAL GRASSLANDS CONGRESS, 18., 1997. Proceedings... Manitoba: Canada, 1997. p.681-689.

JAMIESON, W.S.; HODGSON, J. The effect of variation in sward characteristics upon the ingestive behavior and herbage intake of calves and lambs under continuous stocking management. Grass and Forage Science, v.34, p.273-281, 1979.

LACA, E.A.; DEMMENT, M.W. Modelling intake of a grazing ruminant in a heterogeneous environment. In: INTERNATIONAL SYMPOSIUM ON VEGETATION-HERBIVORE RELATIONSHIPS, 1992, New York. Proceedings... New York: Academic Press, 1992. p.57-76.

LACA, E.A.; UNGAR, E.D.; SELIGMAN, N. et al. Effects of sward height and bulk density on bite dimensions of cattle grazing homogeneous swards. Grass and Forage Science, v.47, p.91-102, 1992.

MARTINICHEN, D. A estrutura do dossel e o comportamento ingestivo de vacas leiteiras em capim-mombaça. 2006. 71f. Tese (Doutorado em Agronomia) - Universidade Federal do Paraná, Curitiba.

MONTAGNER, D.B.; ROCHA, M.G.; SANTOS, D.T. et al. Manejo da pastagem de milheto para recria novilhas de corte. Ciência Rural, v.38, n.8, p.2293-2299, 2008.

NATIONAL RESEARCH COUNCIL - NRC. Nutrient requirements of beef cattle. 7.ed. Washington: National Academy Press, 1996. 242p.

PALHANO, A.L.; CARVALHO, P.C.F.; DITTRICH, J.R. et al. Padrões de deslocamento e procura de forragem de novilhas leiteiras em pastagem de capim-mombaça. Revista Brasileira de Zootecnia, v.35, n.6, p.2253-2259, 2006.

PENNING, P.D.; PARSONS, A.J.; ORR, R.J. et al. Intake and behaviour responses by sheep to changes in sward characteristics under continuous stocking. Grass \& Forage Science, v.46, n.1, p.15-28, 1991

PRACHE, S.; PEYRAUD, J. Préhensibilité de 1'herbe páturée chez les bovins et les ovins. INRA Productions Animales, v.10, p.377-390, 1997.

REGO, F.C.A.; DAMASCENO, J.C.; MARTINS, E.N. et al. Influência de variáveis químicas e estruturais do dossel sobre a taxa de ingestão instantânea em bovinos manejados em pastagens tropicais. Revista Brasileira de Zootecnia, v.35, n.3, p.691-698, 2006.

RESTLE, J.; ROSO, C.; AITA, V. et al. Produção animal em pastagem com gramíneas de estação quente. Revista Brasileira de Zootecnia, v.31, n.3, p.1491-1500, 2002 (Supl.). 
SARMENTO, D.O.L. Comportamento ingestivo de bovinos em pastos de capim marandu submetidos a regimes de lotação contínua. 2003. 76f. Dissertação (Mestrado em Agronomia) - Escola Superior de Agricultura "Luiz de Queiroz". Universidade Federal de São Paulo, Piracicaba.

SILVA, S.C.; CARVALHO, P.C.F. Foraging behaviour and intake in the favourable tropics/sub-tropics. In: McGILLOWAY, D.A. (Ed.) Grassland: a global resource. Dublin: Wageningen Academic Publishers, 2005. p.81-95.

SOLLENBERGER, L.E.; BURNS, J.C. Canopy characteristics, ingestive behavior and herbage intake in cultivated tropical grasslands. In: INTERNATIONAL GRASSLAND CONGRESS,
19., 2001, São Pedro. Proceedings... São Pedro: São Paulo, 2001. p.321-327.

STATISTICAL ANALYSIS SYSTEM - SAS. User's guide: statistics. Version 8.2, Cary: Statistical Analysis System Institute, 2001. 1686p.

STOBBS, T.H. The effect of plant structure on the voluntary intake of tropical pastures. II. Differences in sward structure, nutritive value and bite size of animals grazing Setaria anceps and Chloris gayana at various stages. Australian Journal of Agricultural Research, v. 24 , p.821-829, 1973 .

VAN SOEST, P.J. Nutritional ecology of the ruminant. 2.ed. Ithaca: Cornell, 1994. 476p. 